* Mestra em Direito Negocial pela Universidade Estadual de Londrina. Especialista em Direito Civil e Processo Civil pela Universidade Estadual de Londrina. Advogada.

E-mail: juliana.pavao@hotmail. com

** Doutora em Direito pela Universidade Federal do Paraná. Mestre em Direito Negocial pela Universidade Estadual de Londrina. Professora do Programa de Mestrado em Direito Negocial e da graduação em Direito da Universidade Estadual de Londrina.

E-mail: rita.tarifa@gmail.com

\section{As Disposições sobre Diretivas ANTeCipadas de Vontade No BrasiL}

The Provisions on Advance Directive of Will in Brazil

\section{Juliana Carvalho Pavão* Rita de Cássia Resquetti Tarifa Espolador**}

Como citar: PAVÃO, Juliana Carvalho; ESPOLADOR, Rita de Cássia Resquetti Tarifa. As disposições sobre diretivas antecipadas de vontade no brasil. Revista do Direito Público, Londrina, v. 14, n. 2,p. 168-186, ago. 2019. DOI: 10.5433/24157-108104-1.2019v1 4n2p. 168. ISSN: 1980-511X

Resumo: Atualmente, graças as novas biotecnologias que permitem o prolongamento de forma artificial da vida e a reafirmação do princípio da autonomia da pessoa, questões sobre o término da vida e uma morte digna estão sendo cada vez mais discutidas. Como forma de efetivar os desejos do indivíduo sobre a sua vida e a sua saúde surgiram as diretivas antecipadas de vontade. As diretivas correspondem a negócios biojurídicos nos quais a pessoa deixa expressa a sua vontade sobre tratamentos médicos. No Brasil há uma carência de regulamentação jurídica sobre o assunto, resultando na existência de demandas judiciais requerendo uma decisão sobre a possibilidade de respeitar ou não o disposto nas diretivas. Frente a esse cenário, o trabalho tem como problema discutir a situação das diretivas no Brasil e o papel do Poder Legislativo, concluindo que é necessária uma regulamentação sobre o assunto, devendo haver a discussão e votação dos projetos de lei. O método adotado é o dedutivo, realizando uma análise bibliográfica e jurisprudencial.

Palavras-chave: Autonomia. Diretiva Antecipada de vontade. Legislação. Negócio biojurídico.

Abstract: Today, thanks to the new biotechnologies that allow the artificial prolongation of life and the reaffirmation of the principle of the autonomy of the human person, questions regarding the end of life and a dignified death are being increasingly discussed. Advancement in directives emerged as an effective instrument to guarantee the will of an individual, such as questions regarding their life and health. These directives embody biojuristic acts in which the individual asserts their will over medical treatments. Specifically, in Brazil, there is a lack of legal regulation regarding 
this subject, which has led to many lawsuits that depend on a judge's decision on whether to comply with the provisions of the directives. Nonetheless, this study discusses the current directives in Brazil and the role of the Legislative Branch. Finally, this research concludes that legal regulation is necessary; thus, legislative discussion and debates are necessary for the regulation of this issue. This paper utilized the deductive method, from a bibliographical and jurisprudential analysis.

Keywords: Autonomy. Advance Directive of Will. Legislation. Biojuristic Acts. 


\section{INTRODUÇÃO}

Os negócios jurídicos constituem a base das relações privadas, permitindo com que elas se formem e se desenvolvam. Em decorrência das transformações sociais e tecnológicas, os negócios jurídicos passaram a envolver vários objetos, como o próprio ser humano.

Nesse contexto de novos negócios jurídicos, no caso específico negócios biojurídicos, surgiram as diretivas antecipadas de vontade. As diretivas antecipadas de vontade têm como objeto a disposição da vontade do declarante sobre tratamentos médicos, podendo aceitá-los ou recusá-los. Sua aplicação ocorre normalmente para eventos futuros, quando o paciente não puder expressar a sua vontade.

Esse negócio biojurídico está sendo realizado em território nacional, assim como em outros países. Contudo, no Brasil não há uma regulamentação jurídica sobre a assunto. Frente a isso, a problemática desse trabalho é compreender a situação das diretivas antecipadas de vontade no território nacional e questionar acerca do papel do Poder Legislativo.

A questão é de extrema relevância tendo em vista que se trata de um assunto atual e com uma discussão muito incipiente. Assim, cabe à Academia discutir esse assunto, propondo atitude para os Poderes. Ademais, o tema envolve de forma central o respeito pelo princípio da autonomia do paciente que é importantíssimo para a efetivação dos direitos individuais.

Para poder estudar as diretivas antecipadas de vontade deve, primeiramente, realizar um estudo sobre os negócios jurídicos e negócios biojurídicos, uma vez que as diretivas estão inseridas na segunda categoria. Posteriormente deve-se compreender o que são as diretivas antecipadas de vontade e os casos internacionais relevantes. Por fim, deve-se debater a situação das diretivas no Brasil e as regulamentações em vigor e propostas pelo Poder Legislativo e pelo Conselho Federal de Medicina. O método utilizado é o dedutivo, realizando uma análise bibliográfica e de julgados nacionais e estrangeiras.

Após essa breve introdução deve-se iniciar os estudos pela teoria dos negócios jurídicos e suas modificações.

\section{NEGÓCIOS JURÍDICOS E NEGÓCIOS BIOJURÍDICOS}

As relações privadas se desenvolvem tendo como base os negócios jurídicos. Assim, o Direito Civil, ao regulamentar a questão dos negócios jurídicos, atuou de forma importantíssima para a tratativa das relações entre os particulares.

Diante disso, deve-se destacar que a teoria do negócio jurídico tem sua origem no Direto Civil alemão, no qual foi inserido como categoria do fato jurídico (GALGANO, 1992, p. 39). Então, podia conceituá-lo como "el negocio jurídico ha sido construido como la sola declaración de voluntad, para cuyo pensamiento basta la referencia a un solo individuo" (GALGANO, 1992, p. 39).

O negócio jurídico era compreendido como uma manifestação de vontade das partes 
destinada a produzir efeitos naquela relação. Apesar da origem alemã do instituto, o grande avanço e difusão dessa teoria decorreu dos efeitos da Revolução Francesa, movimento revolucionário de grande relevância para o Direito Civil.

Antes da Revolução, o regime existente na França era o absolutismo, formado pelo rei soberano e a divisão entre clero, burguesia e povo. Devido ao descontentamento da burguesia com os gastos exorbitantes da nobreza e do clero, aquela classe encabeçou uma das revoluções com maiores reflexos no direito, a Revolução Francesa.

Com a Revolução, sob o tema de "liberdade, igualdade e fraternidade", houve a ascensão da burguesia como classe dominante e a mudança na forma de Estado, do Absolutismo para o Estado Liberal. Diante disso, as relações privadas foram separadas das atividades do Estado, resultando na não intervenção do Estado no campo privado (PONA, 2015, p. 127).

Então os particulares podiam se relacionar livremente, uma vez que eram considerados livres e iguais, não cabendo ao Estado determinar os limites para essas tratativas. Isso significa que as atividades do Estado deveriam ficar centradas ao âmbito público, não devendo interferir nas atividades privadas.

Nesse campo os negócios jurídicos cresceram tendo como base a grande liberdade concedida aos indivíduos. Nessa esteira, Francisco Amaral apresenta a conceituação e a noção de negócio jurídico influenciadas pelas ideias revolucionárias:

O negócio jurídico resulta, assim, de um processo de abstração, a partir da liberdade e da igualdade formal de todos perante o direito, processo que se inicia com a Revolução Francesa e que tem por objetivo estabelecer um direito geral e abstrato, aplicável a todos, sem distinção de classe. Vontade e liberdade dentro do processo social e do processo econômico, em que se reconhece a propriedade privada dos bens de produção e a circulação dos bens como processo de cooperação entre os indivíduos (AMARAL, 2014, p. 414).

Frente a isso, os negócios jurídicos tinham como objeto questões patrimoniais, tendo em vista que era a grande preocupação do Direito Civil, o zelo pelo patrimônio. Contudo, o mundo passou por revoluções sociais, industriais e tecnológicas que promoveram mudanças cruciais nas associações humanas.

Ficou evidente que o modelo de Estado Liberal possibilitava relações desequilibradas entre os particulares, havendo a exploração do homem pelo homem. Assim, essa forma de Estado mostrou-se ineficaz diante das mudanças na sociedade. Então, o Estado Liberal entrou em declínio, ascendendo o Estado Intervencionista (PONA, 2015, p. 137).

O Estado Intervencionista tem como função determinar os limites de atuação dos indivíduos no campo privado, não havendo mais a separação entre matéria de ordem pública e de ordem privada. No Brasil ocorreu o processo de constitucionalização do Direito Civil, refletindo no Código Civil de 2002. Esse processo foi descrito por Gustavo Tepedino como:

Trata-se, em uma palavra, de estabelecer novos parâmetros para a definição 
da ordem pública, relendo o direito civil à luz da Constituição, de maneira a privilegiar, insista-se ainda uma vez, os valores não-patrimoniais e, em particular, a dignidade da pessoa humana, o desenvolvimento da sua personalidade, os direitos sociais e a justiça distributiva, para cujo atendimento deve se voltar a iniciativa econômica privada e as situações jurídicas patrimoniais (TEPEDINO, 2004, p. 22).

A dignidade da pessoa humana, assim como valores de ordem não patrimonial constituíram os limites às relações privadas, logo, os negócios jurídicos não têm mais a liberdade de forma ampla, havendo restrições para a própria proteção dos indivíduos.

Nesse novo cenário do Direito Civil Constitucional, o ser humano encontra-se no centro de todo o ordenamento jurídico (TEPEDINO, 2004). Consequentemente, os aspectos existenciais superam os patrimoniais, isso significa a prevalência do plano do ser sobre o ter.

A noção de negócio jurídico não é mais centrada apenas como a manifestação de vontade das partes. Com todas as mudanças de ordem social e jurídica, o negócio jurídico na contemporaneidade deve ser entendido como "mecanismo de cooperação interpessoal e de respeito aos interesses públicos, que são irradiações, respectivamente, da boa-fé objetiva e da função social" (MARQUESI; MARTINS, 2016, p. 143). O negócio jurídico passa a ser entendido como forma de influenciar a vida das partes e exercer reflexos em toda a sociedade, logo, deve haver o respeito ao interesse público (PAVÃO; ESPOLADOR, 2018, p. 251).

Ademais, a visão de negócio jurídico apenas com viés patrimonial não é mais condizente com a realidade do mundo, havendo hoje negócios jurídicos existenciais. O surgimento desses novos tipos de negócios decorreu dos avanços tecnológicos e sociais que geraram situações jurídicas existenciais. Sobre o surgimento das situações jurídicas existenciais e sua relação com o negócio jurídico, Rose Melo Vencelau Meireles afirma "que surgem a partir do ato voluntário, com o intuito criativo, modificativo ou extintivo, têm como substrato fático o negócio jurídico" (MEIRELES, 2009, p. 122-123).

No tocante a formação dos negócios jurídicos existenciais, Paulo Lôbo apresenta:

Em seu cotidiano, na sociedade contemporânea, a pessoa insere-se constantemente em relações jurídicas negociais, às vezes sem consciência disso. Os negócios jurídicos de fornecimento de produtos e serviços públicos, como água, luz, telefonia, são contínuos e vinculam a pessoa contínua e permanentemente. $\mathrm{O}$ transporte público que toma, o alimento que adquire, a chamada telefônica que faz são situações existenciais apreendidas em negócios jurídicos (LOBO, 2009, p. 239-240).

Frente a isso deve-se entender que os negócios jurídicos existenciais envolvem situações jurídicas existenciais, atuando sobre os aspectos essenciais para a vida do ser humano, como água, luz, energia, educação. Assim o objeto desse instrumento é o "mínimo existencial das pessoas, o que lhes confere o caráter de essencialidade, no sentido de que acessam bens jurídicos fundamentais como a liberdade, a honra, a moradia, a educação etc.” (MARQUESI; MARTINS, 2016, p. 152). 
Então, deve-se perceber que a ampliação da teoria dos negócios jurídicos para envolver os negócios existenciais constitui um avanço natural e de acordo com a ordem social presente. Contudo, as transformações não terminaram. As biotecnologias têm apresentado avanços rotineiros cada vez maiores, afetando diretamente a vida do ser humano. Diante dessa nova realidade, na prestação dos serviços médicos surgiram negócios que tinham como objeto o próprio ser humano e o seu corpo, negócios até então nunca sonhados pelo legislador pátrio no momento da confecção do Código Civil de 2002, esses novos tipos de negócios são chamados de negócios biojurídicos.

A terminologia "negócio biojurídico" foi apresentada de forma exclusiva pela autora Rose Melo Vencelau Meireles, tendo essa autora como grande precursora do termo. Infelizmente, o termo "negócios biojurídicos" ainda é pouco difundido na doutrina nacional, em grande medida devido a carência de discussão sobre o assunto. Todavia, dada a especificidade desses tipos de negócios, o presente trabalho entende como essencial a adoção dessa classificação própria para essas formas de negociação (PAVÃO; ESPOLADOR, 2018).

Então, os negócios biojurídicos têm como objeto a saúde e o corpo do agente (MEIRELES, 2016, p. 113), logo, o ser humano atua como sujeito do negócio e seu objeto. Exemplos de negócios biojurídicos são as diretivas antecipadas de vontade, contrato de armazenamento do sangue do cordão umbilical e contrato de reprodução assistida.

A respeito da noção de negócios biojurídicos é interessante observar as palavras de Rose Melo Vencelau Meireles:

A biotecnologia está no cerne dessa questão, na medida em que possibilita a escolha sobre aspectos do próprio corpo que podem promover efeitos constitutivos, modificativos ou extintivos. Nesses casos, conforme antes mencionado, a autonomia ganha a forma de negócio jurídico. Como têm por referencial objetivo aspectos da saúde e do corpo do declarante, foram aqui chamados de biojurídicos (MEIRELES, 2016, p. 115).

A possibilidade de existência desses negócios encontra fundamento na norma civil. As normas sobre negócios jurídicos estão dispostas inicialmente de forma geral no Código Civil, assim podem versar tanto sobre situações patrimoniais como extrapatrimoniais. Ademais, tendo em vista a especificidade dos casos envolvendo negócios biojurídicos, é possível a edição de normas especiais para atuação sobre essas situações. Assim segundo Rose Melo Vencelau Meileres a existência de normas gerais "não significa que não possam ser excepcionalmente afastadas para ceder lugar a normas mais apropriadas para situações jurídicas específicas.” (MEIRELES, 2009, p. 119).

Contudo, nem todas as normas da teoria geral dos negócios jurídicos dispostas no Código Civil podem ser aplicadas aos negócios biojurídicos. Por exemplo o artigo 111 da legislação civil afirma que o silêncio será considerado anuência nos casos que não for necessária a manifestação de vontade. Tendo em vista que negócios biojurídicos atuam sobre o corpo do indivíduo, podendo envolver pessoas incapacitadas de manifestar a sua vontade, compreender o silêncio como anuência 
acarretaria o prejuízo para a autonomia do paciente e para a sua integridade corpórea (NICOLAU, 2003). Frente a isso é importantíssimo que haja regulamentação sobre esses tipos de negócios, uma vez que a sua complexidade e objeto impedem a incidência de todas as normas gerais do Código, havendo hoje a utilização da interpretação com base nos princípios para nortear o entendimento desses instrumentos.

No tocante a ausência de regulamentação dos negócios biojurídicos, Noemi Lidia Nicolau ${ }^{1}$ apresenta suas críticas:

Creemos que, en cambio, es imprescindible contar con un núcleo básico de princípios bien regulados en el Código para ser aplicados a todos los actos de natureza personalísima. En especial nos preocupa el negocio jurídico que nace de la relación médico-paciente, respecto del cual nos parece fundamental incluir en un código de derecho privado una mínima y precisa regulación del principio de autonomia del paciente, el derecho a la información y los elementos esenciales para la validez del negocio jurídico personalísimo, denominado "consentimento" del paciente ${ }^{2}$ (NICOLAU, 2003).

Dessa forma, percebe-se que é muito importante a categorização dos negócios envolvendo a saúde da pessoa, devendo haver uma interpretação e normas específicas. Frente a lacuna legislativa, é fundamental utilizar os princípios constitucionais e civis para nortearem a confecção desses instrumentos.

Os negócios biojurídicos podem ser classificados como os demais tipos de negócios, então eles podem ser: unilaterais ou bilaterais, gratuitos, inter vivo ou mortis causa (MEIRELES, 2016, p. 115). Para ilustrar essa classificação, pode-se pensar no contrato de armazenamento do material genético em uma clínica. Uma pessoa pode decidir congelar seu material genético para utilizar no futuro para a geração da sua prole; o contrato entre a clínica e o paciente ocorre por meio de um contrato de depósito, contudo com algumas características específicas. O depositário deve guardar as células reprodutoras nas melhores condições cientificamente disponíveis, realizando a sua manutenção (FERRAZ, 1991, p. 53). O depositante entrega o seu material e paga uma contraprestação pecuniária pelo depósito. Por fim, a devolução do material deve ser ao depositante ou, em caso de falecimento, a viúva ou a beneficiário indicado por última vontade do depositante (FERRAZ, 1991, p. 53).

Observando as características desse contrato, pode-se concluir que se trata de um negócio bilateral, realizado entre a clínica e o depositante, oneroso, havendo a contraprestação, e inter vivos, uma vez que os efeitos são gerados durante a vida do depositante. Ademais é um negócio

1 A autora não utiliza o termo "negócio biojurídico" mas a terminologia "negocio jurídico personalísimo". Apesar da divergência na terminologia, as noções dos dois negócios é a mesma. Os negócios jurídicos personalíssimos apresentados por Noemi Lidia Nicolau envolvem a integridade física e os direitos da personalidade dos envolvidos. Frente a isso, é possível considerar que as críticas da autora sobre a falta de regulamentação dos negócios jurídicos personalíssimos podem ser aplicadas aos negócios biojurídicos.

2 Tradução livre: "Cremos que, na mudança, é imprescindível contar com um núcleo básico de princípios bem regulados com o Código para serem aplicados a todos os atos de natureza personalíssima. Em especial nos preocupa o negócio jurídico que nasce da relação médico-paciente, a respeito do qual nos parece fundamental incluir em um código de direito privado um mínimo e precisa regulação do princípio da autonomia do paciente, o direito a informação e os elementos essenciais para a validez do negócio jurídico personalíssimo, denominado 'consentimento informado' 
biojurídico por afeta a integridade do ser humano.

Após observar as mudanças na teoria geral dos negócios jurídicos e o surgimento dos negócios biojurídicos, deve iniciar o estudo sobre as diretivas antecipadas de vontade, tipo de negócio biojurídico.

\section{HISTÓRICO DAS DIRETIVAS ANTECIPADAS DE VONTADE}

As diretivas antecipadas de vontade surgiram nos Estados Unidos da América e constituem instrumentos que visam apresentar a vontade do paciente sobre os tratamentos médicos que deseja ou não se submeter em caso de estar incapacitado para expressar a sua vontade. Assim, o paciente deixa a sua vontade expressa quanto aos tratamentos médicos, para que, em caso de impossibilidade de manifestação de vontade, seus médicos saberem como proceder. Dessa forma, a diretiva constitui um mecanismo de efetivação da autonomia do indivíduo, não deixando a decisão sobre o tratamento para os familiares.

A diretiva antecipada de vontade constitui um gênero com duas espécies: living will e durable power of attorney for health (PONA, 2015, p. 37). O primeiro é conhecido no Brasil como Testamento Vital, foi criado em 1967 nos Estados Unidos da América. O Testamento Vital ${ }^{3}$ é o instrumento no qual a pessoa expressa a vontade de não se submeter a determinados tratamentos, quando estiver em estado vegetativo persistente ou doença crônica incurável que a impossibilite de manifestar a sua vontade (DADALTO, 2013, p. 89). Contudo, deve-se entender que é possível que a pessoa expresse no testamento vital o desejo de se submeter a um determinado tratamento médico, logo, o documento pode ser utilizado tanto no aspecto rejeicionista como de aceitação.

Então o conceito de testamento vital deve ser entendido como:

[...] um documento, por meio do qual o indivíduo manifesta antecipadamente a sua vontade em relação aos tratamentos e cuidados médicos que deseja ou não receber nas situações nas quais não possa expressar, por si próprio, sua vontade, de forma temporária ou permanente, esteja ou não em situação de fim de vida (PONA, 2015, p. 48).

Já o mandato duradouro, ou durable power of attorney for health, é:

[...] documento no qual o paciente nomeia um ou mais procuradores que devem ser consultados pelos médicos no caso de incapacidade temporária ou definitiva para tomar alguma decisão sobre o tratamento ou procedimento quando não houver manifestação prévia de vontade, ou, em havendo, se nesta há lacuna obscura que impeça a plena compreensão por parte de quem atende ao paciente

3 O termo "Testamento Vital" é criticado pela doutrina nacional porque aplica o conceito de "testamento', um instituto do direito sucessório com efeitos a partir do falecimento do agente, para um documento sem efeitos sucessórios e com incidência durante a vida da pessoa, sendo aplicado para momentos em que o indivíduo está vivo mas incapaz de expressar sua vontade. Apesar da crítica conter fundamentos razoáveis, o trabalho irá adotar o termo "testamento vital" porque é o mais difundido em território nacional, não cabendo a esse trabalho propor uma mudança terminológica, mas discutir a sua regulamentação. 
(DADALTO, 2013, p. 107).

A grande diferença entre o mandato duradouro e o testamento vital é que naquele um terceiro, já escolhido pelo paciente, irá decidir sobre os tratamentos médicos que o paciente será submetido. Enquanto que no testamento vital a manifestação de vontade quanto aos tratamentos é realizada pelo próprio paciente.

No tocante as diretivas antecipadas de vontade, em caráter geral, dois casos internacionais ganharam grande repercussão, permitindo com que o tema viesse à tona para diversas discussões, os casos foram: Eluana Englaro e Nancy Cruzan.

O primeiro caso, Eluana Englaro, ocorreu na Itália. Eluana era uma mulher que em 1992 sofreu um acidente de carro (STRIANO; BIFULCO; SERVILLO, 2009). A vítima ficou dois meses na UTI, chegando até a abrir os olhos, mas infelizmente não recobrou a consciência. Após passar dois anos nessa situação, os médicos constataram que Eluana estava em estado vegetativo persistente (PONA, 2017, p. 74).

O pai de Eluana, sabendo que a filha não desejava ser mantida viva em caso de inconsciência, iniciou uma batalha judicial para que a vontade da filha fosse observada e a alimentação artificial fosse retirada. Infelizmente, na primeira tentativa que o pedido foi realizado ao Judiciário Italiano, ele foi negado sobre a afirmação que o direito italiano protegia incondicionalmente a vida humana e que a alimentação e hidratação artificial eram cuidados básicos, não tratamentos médicos, logo não poderiam ser recusados pelo paciente (PONA, 2017, p. 74).

Todavia, em 2000 surgiu o argumento de que a alimentação e a hidratação artificial eram tratamentos médicos, logo, poderiam ser recusados pelo paciente. Como base nessa nova argumentação, o genitor de Eluana ingressou novamente ao Judiciário requerendo a interrupção da alimentação. A corte entendeu ser necessário a nomeação de um curador para Eluana devido a um suposto conflito de interesses com o genitor (PONA, 2017, p. 74-75).

Em 2006, em decisão da Primeira Instância de Lecco, foi negado o pedido do pai de Eluana. Felizmente em 2007, a Corte di Cassazione compreendeu ser possível a retirada da nutrição desde que comprovado a vontade de Eluana e que seu estado de saúde fosse irreversível. Diante disso, deve-se observar a decisão da Corte:

Ove il malato giaccia da moltissimi anni (nella specie, oltre quindici) in stato vegetativo permanente, con conseguente radicale incapacità di rapportarsi al mondo esterno, e sia tenuto artificialmente in vita mediante un sondino nasogastrico che provvede alla sua nutrizione ed idratazione, su richiesta del tutore che lo rappresenta, e nel contraddittorio con il curatore speciale, il giudice può autorizzare la disattivazione di tale presidio sanitario (fatta salva l'applicazione delle misure suggerite dalla scienza e dalla pratica medica nell'interesse del paziente), unicamente in presenza dei seguenti presupposti: (a) quando la condizione di stato vegetativo sia, in base ad un rigoroso apprezzamento clinico, irreversibile e non vi sia alcun fondamento medico, secondo gli standard scientifici riconosciuti a livello internazionale, che lasci supporre la benché minima possibilità di un qualche, sia pure flebile, recupero della coscienza e di ritorno ad una percezione del mondo esterno; e (b) sempre che tale istanza sia realmente espressiva, in 
base ad elementi di prova chiari, univoci e convincenti, della voce del paziente medesimo, tratta dalle sue precedenti dichiarazioni ovvero dalla sua personalità, dal suo stile di vita e dai suoi convincimenti, corrispondendo al suo modo di concepire, prima di cadere in stato di incoscienza, l'idea stessa di dignità della persona. Ove l'uno o l'altro presuppoto non sussista, il giudice deve negare l'autorizzazione, dovendo allora essere data incondizionata prevalenza al diritto alla vita, indipendentemente dal grado di salute, di autonomia e di capacità di intendere e di volere del soggetto interessato e dalla percezione, che altri possano avere, della qualità della vita stessa ${ }^{4}$ (ITÁLIA, 2007)

Ademais, para concluir essa decisão, a Corte, dentre diversos argumentos, ponderou o seguinte:

Essi investono la Corte - oltre che del quesito se la terapia praticata sul corpo di XXX YYY, consistente nell'alimentazione e nella idratazione artificiali mediante sondino nasogastrico, possa qualificarsi come una forma di accanimento terapeutico, sull'asserito rilievo che si verserebbe in fattispecie di trattamento invasivo della persona, senza alcun beneficio od utilità per la paziente che vada oltre il prolungamento forzoso della vita, perché oggettivamente finalizzato a preservarne una pura funzionalità meccanica e biologica - anche della questione se ed in che limiti, nella situazione data, possa essere interrotta quella somministrazione, ove la richiesta al riguardo presentata dal tutore corrisponda alle opinioni a suo tempo espresse da XXX su situazioni prossime a quella in cui ella stessa è venuta, poi, a trovarsi e, più in generale, ai di lei convincimenti sul significato della dignità della persona ${ }^{5}$ (ITÁLIA, 2007).

Assim, a Corte analisou o tratamento que a Eluana estava sendo submetida e a utilidade para a manutenção da sua vida. Além disso, a dignidade foi novamente levantada como forma de argumentar sobre o destino da vida dela.

Após essa decisão, em julho de 2008, a Corte de Apelação de Milão considerou que

4 Tradução livre: "Onde o paciente esteve deitado por muitos anos (neste caso, mais de quinze) em um estado vegetativo permanente, com uma consequente incapacidade radical de se relacionar com o mundo exterior, e é mantido vivo artificialmente por meio de sonda nasogástrica que provê sua nutrição e hidratação, a pedido do tutor que o representa, e em contradição com o curador especial, o juiz pode autorizar a desativação deste serviço de saúde (sujeito à aplicação das medidas sugeridas pela ciência e prática médica no interesse do paciente), somente na presença dos seguintes suposições: (a) quando a condição de estado vegetativo é, com base em uma apreciação clínica rigorosa, irreversível e não há base médica, de acordo com padrões científicos internacionalmente reconhecidos, o que sugere a menor possibilidade de alguns, embora débil, recuperação da consciência e retorno a uma percepção do mundo, por exemplo Terno; e (b) desde que essa solicitação seja realmente expressiva, baseada em evidências claras, inequívocas e convincentes, da própria voz do paciente, tirada de suas declarações anteriores ou de sua personalidade, seu estilo de vida e suas convicções, correspondendo ao seu modo de conceber, antes de cair num estado de inconsciência, a própria ideia da dignidade da pessoa. Se um ou outro pressuposto não existir, o juiz deve negar a autorização, uma vez que o direito à vida deve ter prevalência incondicional, independentemente do grau de saúde, autonomia e capacidade de compreensão e da vontade do sujeito interessado. e da percepção que os outros podem ter da qualidade de vida em si ."

5 Tradução livre: "Eles investem na Justiça - além da questão de saber se a terapia praticada no corpo de YYY XXX, que consiste em alimentação artificial e hidratação por sonda nasogástrica, pode ser qualificada como uma forma de obstinação terapêutica, sobre a suposta importância que seria paga neste caso. tratamento invasivo da pessoa, sem qualquer benefício ou utilidade para o paciente que vá além do prolongamento forçado da vida, objetivamente objetivando preservar uma funcionalidade puramente mecânica e biológica - também da questão se e em que medida, na situação dada, pode ser interrompida aquela administração, onde o pedido a este respeito submetido pelo guardião corresponde às opiniões expressas na altura por XXX em situações próximas àquela em que ela mesma veio, então, para se encontrar e, mais geralmente, às suas convicções no significado de dignidade da pessoa" 
os requisitos exigidos pela Corte di Cassazione estavam preenchidos (PONA, 2017, p. 75-76). Assim, compreendeu que as provas da vontade de Eluana estavam expressas em seus diários; além disso, haviam testemunhas que depuseram sobre as vontades dela.

Apesar do preenchimento dos requisitos, o pai de Eluana não conseguiu interromper imediatamente a alimentação artificial da sua filha. Porque houve um pedido para a Corte Constitucional afirmando que haveria um conflito de competência sobre a decisão entre as atribuições do Parlamento e do Judiciário (PONA, 2017, p. 76).

A Corte di Cassazione entendeu que não havia conflito de atribuições sobre a decisão do caso Englaro. Além disso, afirmou que o assunto não estava esgotado, podendo o Parlamento regulamentar de forma específica a questão:

che la vicenda processuale che ha originato il presente giudizio non appare ancora esaurita, e che, d'altra parte, il Parlamento può in qualsiasi momento adottare una specifica normativa della materia, fondata su adeguati punti di equilibrio fra i fondamentali beni costituzionali coinvolti ${ }^{6}$ (ITÁLIA, 2008).

Frente a essa decisão, foi possível a retirada da alimentação artificial da paciente Eluana, resultando na terminalidade da sua vida. Assim, esse caso tornou-se um marco para o direito italiano no tocante a autonomia do paciente e a sua vida.

Outro caso de grande repercussão no cenário internacional foi de Nancy Cruzan nos Estados Unidos da América. A norte-americana sofreu um acidente de carro em 1983, ficando muito ferida. Como consequência do desastre, Nancy ficou em estado vegetativo persistente, não tendo mais consciência e precisando se alimentar e se hidratar de forma natural, sendo necessário a utilização de alimentação por aparelhos (RAPOSA, 2011, p. 173).

Tendo os pais de Nancy o conhecimento que a filha não desejava ser mantida viva por aparelhos estando completamente inconsciente, e constatando que o estado da paciente era irreversível, os genitores ingressarem no Judiciário Americano a fim de obterem a autorização para a retirada da alimentação (RAPOSA, 2011, p. 173).

Sobre a manutenção da vida em caso de terminalidade, a Suprema Corte Norte-Americana pontuou de forma bem esclarecida:

The Cruzan family's continuing concern provides a concrete reminder that Nancy Cruzan's interests did not disappear with her vitality or her consciousness. However commendable may be the State's interest in human life, it cannot pursue that interest by a propriating Nancy Cruzan's life as a symbol for its own purposes. Lives do not exist in abstraction [p357] from persons, and to pretend otherwise is not to honor but to desecrate the State's responsibility for protecting life. A State that seeks to demonstrate its commitment to life may do so by aiding those who are actively struggling for life and health. In this endeavor, unfortunately, no State can lack for opportunities: there can be no need to make an example of tragic

6 Tradução livre: “[...] que o julgamento que deu origem a este julgamento não parece ter sido esgotado e que, por outro lado, o Parlamento pode a qualquer momento adotar uma regulamentação específica sobre o assunto, baseada em pontos de equilíbrio adequados entre os ativos constitucionais fundamentais envolvidos [...]" 
cases like that of Nancy Cruzan (UNITED STATES, 1990).

Deve-se sempre considerar que mesmo a pessoa estando incapacitada de expressar a sua vontade no momento, não se pode olvidar que aquele indivíduo apresenta interesses concretos. Assim, a sua vontade manifestada em períodos de consciência deve ser considerada quando estiver inconsciente.

Frente a isso, o tribunal compreendeu que, desde que fosse demonstrado de forma absoluta a vontade manifestada anteriormente por Nancy, os aparelhos de alimentação poderiam ser retirados. Os pais conseguiram comprovar a vontade da filha por meio de prova testemunhal, obtendo a autorização judicial para a retirada dos tubos de alimentação, o que resultou no falecimento de Nancy em 1990 (RAPOSA, 2011, p. 173-174).

Esses dois casos ilustram a batalha judicial que duas famílias enfrentaram para conseguirem fazer com que as vontades das filhas fossem realizadas. Assim como a pessoa, em momento de lucidez, pode decidir no tocante aos rumos da sua vida e dos tratamentos médicos, ela também deve ser capaz de poder deixar as suas vontades expressas para que sejam seguidas quando ela estiver inconsciente.

Em ambos os casos as famílias conheciam e tinham provas das vontades das filhas, que estavam em estado vegetativo irreversível. Contudo, levaram anos para que os desejos das filhas fossem respeitados, havendo assim um prolongamento da vida sem haver reais chances de melhoras no quadro clínico das pacientes.

Com esses casos ascendeu as discussões sobre as diretivas antecipadas de vontade, devendo analisar no último tópico como essas diretivas são regulamentadas no cenário nacional.

\section{A REGULAMENTAÇÃO DAS DIRETIVAS ANTECIPADAS DE VONTADE NO BRASIL}

Conforme apresentado anteriormente, as diretivas antecipadas de vontade constituem negócios biojurídicos, nos quais o indivíduo deixa registrada a sua vontade no tocante ao seu corpo e sua saúde para que seja respeitada quando estiver impossibilitado de manifestar seus desejos. Então, por meio das diretivas há o conhecimento dos desejos da pessoa, podendo ser sobre negativa a determinado tratamento ou autorização.

As diretivas antecipadas de vontade são realizadas com base no princípio da autonomia dos particulares, sendo realizadas na forma de negócios biojurídicos, uma vez que envolvem o sujeito e seu corpo.

Segundo Everton Willian Pona ${ }^{8}$ as características desse negócio são: unilateral, gratuito,

7 Tradução livre: “A contínua preocupação da família Cruzan fornece um lembrete concreto de que os interesses de Nancy Cruzan não desapareceram com sua vitalidade ou sua consciência. Por mais louvável que seja o interesse do Estado pela vida humana, não pode perseguir esse interesse adotando a vida de Nancy Cruzan como um símbolo para seus próprios fins. As vidas não existem na abstração das pessoas, e fingir o contrário não é honrar, mas profanar a responsabilidade do Estado por proteger a vida. Um Estado que procura demonstrar seu compromisso com a vida pode fazê-lo, ajudando aqueles que estão lutando ativamente por vida e saúde. Neste esforço, infelizmente, nenhum Estado pode carecer de oportunidades: não pode haver necessidade de fazer um exemplo de casos trágicos como o de Nancy Cruzan."

8 O autor utiliza o termo "negócio jurídico" de forma ampla para se referir as diretivas antecipadas de vontade, assim 
revogável e personalíssimo (PONA, 2015, p. 170). A unilateralidade ocorre porque deve ser feito apenas pelo paciente, orientado pelo médico sobre todas as consequências dos procedimentos médicos. Dada a complexidade dos tratamentos médicos, é essencial que haja os esclarecimentos por um profissional da saúde quanto aos riscos e benefícios, todavia, ele não configura como parte integrante do negócio, apenas um auxiliar.

A gratuidade é uma característica obrigatória, tendo em vista que o objeto é o próprio indivíduo e o seu corpo. Assim, pela legislação nacional é vedado qualquer estipulação pecuniária sobre a integridade física do ser humano.

O ato deve ser realizado pelo próprio paciente, não cabendo a utilização de um procurador, uma vez que é um mecanismo de concretização da autonomia do paciente. Dito isso, o negócio é personalíssimo. Ademais, é cabível a revogação a qualquer momento pelo indivíduo.

No Brasil não há regulamentação civil vigente sobre as diretivas. Existindo apenas, no âmbito jurídico, o Enunciado no 37 do Conselho Nacional de Justiça (2012):

ENUNCIADO $\mathrm{N}^{\circ} 37$ As diretivas ou declarações antecipadas de vontade, que especificam os tratamentos médicos que o declarante deseja ou não se submeter quando incapacitado de expressar-se autonomamente, devem ser feitas preferencialmente por escrito, por instrumento particular, com duas testemunhas, ou público, sem prejuízo de outras formas inequívocas de manifestação admitidas em direito.

Esse enunciado foi apresentado na Jornada de Direito da Saúde, indicando uma preocupação jurídica com a regulamentação da questão. Contudo, infelizmente não existe nenhum dispositivo civil em vigor no país, havendo regulamentação pelo órgão de classe médico.

Então, o Conselho Federal de Medicina aborda a questão por meio da Resolução no 1.995/2012. Segundo a Resolução as diretivas são “o conjunto de desejos, prévia e expressamente manifestados pelo paciente, sobre cuidados e tratamentos que quer, ou não, receber no momento em que estiver incapacitado de expressar, livre e autonomamente, sua vontade." (CONSELHO FEDERAL DE MEDICINA, 2012).

Além disso, a Resolução prevê que as diretivas devem ser aplicadas quando o paciente estiver incapaz de se comunicar "ou de expressar de maneira livre e independente suas vontades." No parágrafo terceiro do artigo segundo da Resolução fica evidente que as diretivas devem sempre prevalecer no tocante aos tratamentos médicos sobre o paciente, inclusive sobre os desejos dos familiares. Todavia, a Resolução afirma que caso o documento disponha de forma contrária aos preceitos do Código de Ética Médica, o médico não poderá considerá-la (CONSELHO FEDERAL DE MEDICINA, 2012).

No cenário nacional iniciou o debate sobre a questão das diretivas antecipadas de vontade há pouco tempo. Havendo ainda uma carência legislativa sobre o assunto, mas uma regulamentação por parte do Conselho Federal de Medicina. Frente a existência do direito à vida no âmbito 
constitucional e o princípio da autonomia para a confecção da diretiva, os médicos encontram-se em uma situação muito delicada sobre a atitude a ser realizada, na medida em que não existe uma resposta legislativa sobre a adoção da diretiva.

Dessa forma, quando há a recusa do paciente sobre um tratamento, manifestando de forma escrita ou verbal ${ }^{9}$, o hospital recorre ao Judiciário para sanar a questão, porque existe o entendimento da classe médica que a vida deve ser preservada, conforme princípio constitucional.

Então, na jurisprudência brasileira pode-se encontrar dois julgados que versaram sobre a manifestação do paciente de recusa do tratamento, realizando para isso uma diretiva antecipada de vontade.

O primeiro caso de 20 de novembro de 2013 foi julgado pelo Tribunal de Justiça do Rio Grande do Sul. Nesse julgado, um paciente estava com um pé necrosado e negou à amputação. No momento da negativa o paciente estava consciente e esclarecido sobre os riscos da não realização do procedimento. Apesar da manifestação clara do paciente, o hospital ingressou com o pedido para a realização do procedimento, sendo indeferido em primeira instância.

Na segunda instância, o Tribunal manteve a decisão do juiz a quo, apresentando a seguinte ementa do caso:

\section{APELAÇÃO CÍVEL. ASSISTÊNCIA À SAÚDE. BIODIREITO. ORTOTANÁSIA. TESTAMENTO VITAL.}

1. Se o paciente, com o pé esquerdo necrosado, se nega à amputação, preferindo, conforme laudo psicológico, morrer para "aliviar o sofrimento"; e, conforme laudo psiquiátrico, se encontra em pleno gozo das faculdades mentais, o Estado não pode invadir seu corpo e realizar a cirurgia mutilatória contra a sua vontade, mesmo que seja pelo motivo nobre de salvar sua vida.

2. O caso se insere no denominado biodireito, na dimensão da ortotanásia, que vem a ser a morte no seu devido tempo, sem prolongar a vida por meios artificiais, ou além do que seria o processo natural.

3. O direito à vida garantido no art. $5^{\circ}$, caput, deve ser combinado com o princípio da dignidade da pessoa, previsto no art. $2^{\circ}$, III, ambos da CF, isto é, vida com dignidade ou razoável qualidade. A Constituição institui o direito à vida, não o dever à vida, razão pela qual não se admite que o paciente seja obrigado a se submeter a tratamento ou cirurgia, máxime quando mutilatória. Ademais, na esfera infraconstitucional, o fato de o art. 15 do CC proibir tratamento médico ou intervenção cirúrgica quando há risco de vida, não quer dizer que, não havendo risco, ou mesmo quando para salvar a vida, a pessoa pode ser constrangida a tal. 4. Nas circunstâncias, a fim de preservar o médico de eventual acusação de terceiros, tem-se que o paciente, pelo quanto consta nos autos, fez o denominado testamento vital, que figura na Resolução no 1995/2012, do Conselho Federal de Medicina.

5. Apelação desprovida (RIO GRANDE DO SUL, 2013).

O segundo julgado também é o Tribunal de Justiça do Rio Grande do Sul de 3 de setembro

9 Conforme disposto na Resolução do Conselho Federal de Medicina, não é obrigatório que o paciente deixe por escrito a sua vontade, podendo expressá-la para o médico que procederá com a anotação no prontuário. Diante da segurança jurídica, compreendemos que o mais adequado seria a disposição escrita da vontade. 
de 2015. No caso, um paciente negou a realização de um tratamento médico e sua madrasta, conhecendo a vontade do enteado, assinou o termo de recusa do tratamento. Apesar da nítida vontade do paciente, houve o pedido de autorização judicial para a realização do procedimento. Felizmente, a vontade do paciente preponderou na decisão do Tribunal.

AGRAVO DE INSTRUMENTO. DIREITO PÚBLICO NÃO ESPECIFICADO. DIREITO À SAÚDE. autorização para realização de procedimento cirúrgico. NEGATIVA DO PACIENTE. necessidade de ser respeitada a vontade do PACIENTE.

1. O direito à vida previsto no artigo $5^{\circ}$ da Constituição Federal não é absoluto, razão por que ninguém pode ser obrigado a se submeter a tratamento médico ou intervenção cirúrgica contra a sua vontade, não cabendo ao Poder Judiciário intervir contra esta decisão, mesmo para assegurar direito garantido constitucionalmente. 2. Ademais, considerando que "não se justifica prolongar um sofrimento desnecessário, em detrimento à qualidade de vida do ser humano", o Conselho Federal de Medicina (CFM), publicou a Resolução $n^{\circ}$ 1.995/2012, ao efeito de dispor sobre as diretivas antecipadas de vontade do paciente, devendo sempre ser considerada a sua autonomia no contexto da relação médico-paciente.

3. Hipótese em que o paciente está lúcido, orientado e consciente, e mesmo após lhe ser explicado os riscos da não realização do procedimento cirúrgico, este se nega a realizar o procedimento, tendo a madrasta do paciente, a seu pedido, assinado termo de recusa de realização do procedimento em questão, embora sua esposa concorde com a indicação médica.

4. Por essas razões, deve ser respeitada a vontade consciente do paciente, assegurando-lhe o direito de modificar o seu posicionamento a qualquer tempo, sendo totalmente responsável pelas consequências que esta decisão pode lhe causar.

NEGADO SEGUIMENTO AO RECURSO (RIO GRANDE DO SUL, 2015, grifo do autor).

Em ambos os casos o Tribunal compreendeu de forma muito acertada que a vontade do paciente, lúcida e esclarecida, deveria prevalecer sobre a sua saúde. Nesses casos, os pacientes estavam lúcidos no momento de ingresso no Judiciário, contudo, assim como os casos internacionais, houve a manifestação da vontade dos indivíduos, sendo denominadas de diretivas antecipadas, entretanto para serem observadas foi necessário utilizar-se do Poder Judiciário.

No contexto nacional a existência dessa instabilidade quanto ao cumprimento das diretivas dá-se em grande parte a falta de discussão e regulamentação da questão, gerando uma grande insegurança para os profissionais da saúde. Frente a isso, é competência do Estado regulamentar a questão para que os direitos do paciente e o respeito ao princípio da autonomia sejam preservados.

Nesse sentido, existe no Senado Federal o Projeto de Lei no 149 de 2018 que dispõe sobre as diretivas antecipadas de vontade sobre tratamento de saúde. Atualmente, o projeto está aguardando designação do relator na Comissão de Assuntos Sociais.

Dentre as diversas justificativas, o senador Lasier Martins, autor do projeto, apresenta como objetivo do projeto a supressão da lacuna existente no Brasil sobre o assunto, tendo como 
princípio o respeito à dignidade e à autonomia do paciente. Caso o texto integral do projeto seja aprovado as diretivas deverão ser realizadas por escritura pública lavrada em Cartório, isso significa que haverá uma formalidade legal com relação a esse documento (BRASIL, 2018).

A possibilidade de alteração das diretivas é disposta no art. $4^{\circ}$ do projeto, podendo inclusive ser na forma verbal ao prestador dos cuidados à saúde. Então, nesse caso cabe ao médico assistente a realização do registro no prontuário sobre as alterações (BRASIL, 2018).

Um artigo importante do projeto que deve ser destacado é o artigo $5^{\circ}$. Segundo esse artigo, as diretivas deverão ser obrigatoriamente acatadas pelos profissionais de saúde e de serviço, sejam públicos ou privados, assim como pelos familiares, responsáveis legais e representantes do declarante. Contudo, é possível a recusa da observância das diretivas nos seguintes casos: se estiverem contrárias aos preceitos éticos da profissão médica; em situação de urgência ou perigo imediato para a vida do paciente; não houver tempo hábil para acessar a diretiva sem causar risco à saúde ou à vida do declarante; ou quando a diretiva estiver em evidente desatualização com relação ao progresso dos meios terapêuticos (BRASIL, 2018).

Assim, o Projeto de Lei consegue determinar pontos importantes para a devida regulamentação das diretivas. Além disso, proporciona segurança jurídica para o declarante e a equipe de saúde envolvida.

Além desse projeto de alcance nacional, no estado do Paraná foi apresentado no ano de 2019 o Projeto de Lei $\mathrm{n}^{\circ} 19$ para dispor sobre as diretivas antecipadas de vontade no Estado. O projeto apresenta um foco maior na organização dos cuidados paliativos.

No tocante a formalidade das diretivas, o projeto as denomina como "Instruções Prévias da Vontade em Saúde" e não apresenta requisitos formais específicos. Apenas no art. $7^{\circ}$ é disposto que o governo estadual deve criar e regulamentar o registro estadual das diretivas, todavia realiza a ressalva que cabe a legislação federal aprovar esse ponto, apresentando um Registro Nacional (BRASIL, 2019).

Ressalva-se que as disposições sobre as diretivas antecipadas de vontade devem ser tratadas de forma geral pela União, por se tratar de matéria civil, logo, é competência do governo federal de acordo com o art. 22, I da Constituição Federal. Entretanto, os Estados Membros podem legislar de forma complementar sobre questões específicas, assim, é possível a existência de lei estadual.

Diante da ausência legislativa em vigor no país, esses dois projetos de lei são fundamentais para possibilitar a devida regulamentação da questão das diretivas antecipadas de vontade, fornecendo segurança jurídica e respeito à autonomia dos indivíduos.

\section{CONCLUSÃO}

Diante do exposto, pode-se observar que os negócios jurídicos passaram por transformações. Graças aos avanços tecnológicos na área da saúde, hoje existem tecnologias capazes de afetar diretamente a vida e a saúde do indivíduo, possibilitando uma manutenção da 
sua vida além do imaginado.

Entretanto a melhoria da manutenção da vida gera indagações sobre a qualidade da vida e a dignidade da morte. Ademais, as escolhas das pessoas quanto a sua saúde e o encerramento da vida passam a ser cada vez mais discutidas. Assim, nesse cenário surgiram as diretivas antecipadas de vontade, um negócio biojurídico confeccionado com o intuito de manifestar os desejos do declarante sobre tratamentos médicos. Por meio das diretivas, as pessoas terão conhecimento sobre a vontade do paciente, mesmo no caso dele estar inconsciente.

O respeito pela vontade do paciente em detrimento da vida resultou em disputas judiciais no âmbito internacional. Dois casos muito conhecidos, um nos Estados Unidos da América e outro na Itália, ilustram a luta de familiares para que os desejos de seus entes queridos fossem respeitados e tivessem uma morte digna.

Frente a essa repercussão internacional e a vontade das pessoas de poderem tomar decisões sobre a sua vida e o seu corpo, começou a discutir no Brasil sobre as diretivas antecipadas de vontade. Infelizmente a discussão ainda é muito incipiente, carecendo de uma legislação em vigor sobre o assunto.

O Conselho Federal de Medicina regulamenta a questão, entretanto ainda existe muita insegurança, principalmente pelos profissionais da saúde, sobre a aplicação das diretivas, especialmente quando envolver o risco de vida para o paciente. Isso resultou em demandas judiciais para suprimir essa lacuna jurídica e fornecerem uma resposta para essa latente demanda.

Todavia, é dever do Estado a regulamentação, via Poder Legislativo, sobre a questão, fornecendo uma legislação de caráter nacional no tocante as diretivas. Isso fará com que não seja mais necessário sempre recorrer ao Poder Judiciário.

Felizmente hoje existem dois projetos de lei dispondo sobre as diretivas antecipadas de vontade em âmbito federal e estadual. Esses projetos correspondem a uma atitude louvável do legislador de dispor sobre o assunto, e assim fornecer maior fundamento para que as diretivas sejam realizadas e sejam respeitadas. Assim, é papel essencial e iminente do legislador debater esses projetos e votar para que essa demanda social seja suprida.

\section{REFERÊNCIAS}

AMARAL, Francisco. Direito civil: introdução. 8. ed. Rio de Janeiro: Renovar, 2014.

BRASIL. Assembleia Legislativa do Estado do Paraná. Projeto de Lei no 19/2019. Dispõe sobre as diretivas antecipadas de vontade, a organização dos cuidados paliativos no Paraná. Autoria do Deputado Michele Caputo. Disponível em: http://portal.alep.pr.gov.br/modules/mod_legislativo_ arquivo/mod_legislativo_arquivo.php?leiCod=81674\&tipo=I. Acesso em: 10 abr. 2019.

BRASIL. Senado Federal. Projeto de Lei do Senado n⿳ 149 de 2018. Dispõe sobre as diretivas antecipadas de vontade sobre tratamentos de saúde. Autoria: Senador Lasier Martins. Disponível em: https://legis.senado.leg.br/sdleg-.getter/ documento?dm=7653326\&ts=1553282043981\&disposition=inline. Acesso em: 10 abr. 2019. 
CONSELHO FEDERAL DE MEDICINA (Brasil). Resolução CFM no 1.995/2012. Dispõe sobre as diretivas antecipadas de vontade dos pacientes. Diário Oficial da União: Seção 1, Brasília, DF, p. 269-70, 31 ago. 2012, Disponível em: http://www.portalmedico.org.br/resolucoes/ CFM/2012/1995_2012.pdf. Acesso em: 10 abr. 2019.

DADALTO, Luciana. Testamento vital. 2. ed. Rio de Janeiro: Lumen Juris, 2013.

FERRAZ, Sérgio. Manipulações biológicas e princípios constitucionais: uma introdução. Porto Alegre: Sérgio Antônio Fabris, 1991.

GALGANO, Francesco. EI negocio jurídico. Traducción de Francisco de Paula Blasco Gascó, Lorenzo Prats Albentosa. Valencia: Tirant lo blanch, 1992.

ITALIA. Corte Constituzionale. Ordinanza no 334 (Confronti di Attribuzione). Relator: Ugo de Siervo. Camara dei Deputati e Senato della Repubblica vs. Corte di Cassazione e Corte di Appelo di Milano. Roma, 8 ottobre, 2008. Disponível em: https://tinyurl.com/yyr2n4ko. Acesso em 9 abr 2019.

ITALIA. Supreme Corte di Cassazione. Sentenza no 21748. Sezione Prima Civile. Relatores: A. Giusti. Roma. 16 ottobre 2007. Disponível em: https://it.wikisource.org/wiki/Sentenza_Corte_ di_Cassazione_n._21748-2007. Acesso em: 9 abr 2019.

MARQUESI, Roberto Wagner; MARTINS, Priscila Machado. Eficácia horizontal dos direitos fundamentais e negócios jurídicos existenciais. In: PONA, Éverton Willian; AMARAL, Ana Cláudia Corrêa Zuin Mattos do; MARTINS, Priscila Machado (coord.). Negócio jurídico e liberdades individuais: autonomia privada e situações jurídicas existenciais. Curitiba: Juruá, 2016. p. 139-156.

MEIRELES, Rose Melo Vencelau. Autonomia privada e dignidade humana. Rio de Janeiro: Renovar, 2009.

MEIRELES, Rose Melo Vencelau. Negócios Biojurídicos. In: PONA, Éverton Willian; AMARAL, Ana Cláudia Corrêa Zuin Mattos do; MARTINS, Priscila Machado (coord.).

Negócio jurídico e liberdades individuais: autonomia privada e situações jurídicas existenciais. Curitiba: Juruá, 2016. p. 109-120.

NICOLAU, Noemí Lídia. Una pecularidad del modelo jurídico derivado del nuovo código civil brasileño. Rivista di Diritto dell'Integrazione e Unificazione del Diritto in Europa e in America Latina, v. 16, 2003.

PAVÃO, Juliana Carvalho; ESPOLADOR, Rita de Cássia Resquetti Tarifa. Paradigma Contemporâneo e os negócios biojurídicos: seleção embrionária. Scientia Iuris, Londrina, v. 22, n. 2, p. 244-271, jul.2018. DOI: 10.5433/2178-8189.2018v22n2p244.

PONA, Éverton Willian. Enquanto você dormia: fim de vida e o debate sobre o caso Eluana Englaro: o testamento vital faria diferença? In: VEIRA, Tereza Rodrigues; CARDIN, Valéria Silva Galdino; GOMES, Luiz Geraldo do Carmo (org.). Bioética \& cinema. Maringá: Miraluz, 2016. p. 67-88. 
PONA, Éverton Willian. Testamento vital e autonomia privada: fundamentos das diretivas antecipadas de vontade. Curitiba: Juruá, 2015.

RAPOSA, Vera Lúcia. Directivas antecipdas de vontade: em busca da lei perdida. Revista do Ministério Público, Lisboa, n. 125, p. 169-217. jan./mar. 2011. Disponível em: http://rmp. smmp.pt/wp-content/uploads/2011/05/Revista_MP_N125_EstudosReflex_5.pdf. Acesso em: 9 abr. 2019.

RIO GRANDE DO SUL. Tribunal de Justiça. Agravo de Instrumento: AI 70065995078 - RS. Agravo de instrumento. direito público não especificado. Direito à saúde. Autorização para realização de procedimento cirúrgico. Relator: Sergio Luiz Grassi Beck. Publicado DJ, 10 set. 2015. Disponível em: https://tj-rs.jusbrasil.com.br/jurisprudencia/230669134/agravo-deinstrumento-ai-70065995078-rs/inteiro-teor-230669136?ref=juris-tabs. Acesso em: 10 abr. 2019.

RIO GRANDE DO SUL. Tribunal de Justiça. Apelação Cível: AC 70054988266 - RS. Órgão Julgador: $1^{a}$ Câmara Cível. Relator: Irineu Mairani. Data de Julgamento: 20 de novembro de 2013. Disponível em: https://tj-rs.jusbrasil.com.br/jurisprudencia/113430626/apelacao-civel-ac70054988266-rs. Acesso em: 10 abr. 2019.

STRIANO, Pasquale; BIFULCO, Francesca; SERVILLO, Giuseppe. The saga of Eluana Englaro: another tragedy feeding the media. Intensive Care Medice, v. 35, n. 6, p. 1129-1131, june 2009.

TEPEDINO, Gustavo. Temas de direito civil. 3. ed. Rio de Janeiro: Renovar, 2004.

UNITED STATES. Supreme Court. Cruzan by CRuzan v. Director, Missouri Departmente of Health (nº 88-1503). 25 jun 1990. Disponível em: https://www.law.cornell.edu/supremecourt/ text/497/261. Acesso em: 10 abr 2019.

Como citar: PAVÃO, Juliana Carvalho; ESPOLADOR, Rita de Cássia Resquetti Tarifa. As disposições sobre diretivas antecipadas de vontade no brasil. Revista do Direito Público, Londrina, v. 14, n. 2, p. 168-186, ago. 2019. DOI: 10.5433/24157-108104-1.2019v14n2p. 169. ISSN: $1980-511 \mathrm{X}$

Recebido em: 10/06/2019.

Aprovado em: 19/08/2019. 